\title{
pro.posições
}

\section{Como lágrimas na chuva? \\ O estudo da memória e a construção da memória educacional}

Like tears in rain?

\section{The study of the memory and the construction of educational memory}

*Departamento de Filosofia e História da Educação, Faculdade de Educação, Universidade Estadual de Campinas, Campinas, SP, Brasil.paulilo@unicamp.br

**Departamento de Ciências Sociais na Educação, Faculdade de Educação, Universidade Estadual de Campinas, Campinas, SP, Brasil.dmazza@unicamp.br

\begin{abstract}
Resumo
Este artigo analisa as práticas preservacionistas do Centro de Memória da Educação da Faculdade de Educação da Universidade Estadual de Campinas (CME/FE-Unicamp). O propósito do trabalho é duplo. Propõe-se, por um lado, explorar a memória como tema de estudo da historiografia. E, por outro lado, analisar as transformações de propósito do CME/FE-Unicamp entre 2001 e 2015. Argumenta-se que, em sua configuração histórica específica, o CME/FE-Unicamp pode oferecer uma via produtiva para os estudos da memória educacional. Desse modo, o CME/FE-Unicamp será apresentado como uma das instituições que contribui para pensar alguns dos dilemas da relação entre memória e educação. Palavras-chave: memória da educação, arquivos, centros de documentação, cultura escolar e patrimônio.
\end{abstract}




\section{pro.posições}

ISSN 1980-6248

\section{Abstract}

In this article, the preservationist practices of the Centre for the Memory of Education of the Education College in the University of Campinas (CME/FE-Unicamp) is analyzed. The purpose of this study is dual. It proposes an exploration, on the one hand, the memory as theme of historiography study. It seeks, on the other hand, to analyze the CME/FE-Unicamp purpose transformations between 2001 and 2015. We argue that, in its specific bistorical configuration, the CME/FE-Unicamp may be productive path for educational memory studies. In this approach, the CME/FE-Unicamp will be presented as one of the institutions that have positively contributed to the thinking of some of the dilemmas between memory and education.

Keywords: memory of education, archives, documentation centre, scholar culture and patrimony.

Eu vi coisas que os bumanos não acreditariam.

Naves de combate em chamas em Orion.

Vi brilhar raios-C na escuridão próxima do portal de Tannbäuser.

Todos estes momentos se perderão no tempo... como lágrimas na chuva.

É hora de morrer

(Blade Runner, 1982.)

Parece paradoxal iniciar um texto que se propõe a refletir sobre a memória e a educação com a fala do replicante Roy Batty que, no filme Blade Runner-- o caçador de Androides, representa um guerreiro da linhagem "Nexus 6", feito para trabalhar como escravo em projetos humanos de conquistas planetárias.

No filme, Roy Batty pertence a uma geração de androides que difere das anteriores, porque os elementos rígidos do seu mecanismo produziram junções transmissoras artificiais capazes de relacionar informações sobre situações reais, sentimentos humanos e potenciais de comportamentos. A capacidade de adquirir, armazenar e recuperar informações disponíveis vinculou-se a sentimentos e comportamentos, ou seja, a experiências significativas que produzem amor, ódio, alegria, tristeza e medo. Roy se junta a outros replicantes, reage de 


\section{pro.posıções}

modo organizado, lidera uma rebelião e foge para a Terra em busca de seu criador, pois tem plena consciência de que sua geração de replicantes quase perfeita sofre de uma imperfeição mecânica: a finitude. A linhagem Nexus 6 vive pouco e tem o tempo de vida definido em seu mecanismo. Entretanto, ele ama a vida, porque as memórias inscritas em seu mecanismo guardam sentimentos que o vinculam afetivamente com sua história, com os outros androides, os humanos, o tempo e o espaço. Ele deseja alterar o tempo de morrer para tempo de viver (Suppia, 2007).

Roy se coloca numa cruzada entre mundos em busca do seu criador, tendo como objetivo descobrir novas tecnologias e técnicas que aperfeiçoem o seu mecanismo (Alves, 2004). Ele ama, chora, sente dor, luta e, no momento de sua morte, se assume como um guardião da vida e, num ato de fraternidade, vinga a morte de outros androides, preserva a vida de Deckard - o caçador de androides -, busca a si mesmo por meio das experiências vividas e decreta que com sua morte morre também uma parte da história guardada na sua memória. Ele diz: "Eu vi coisas que os humanos não acreditariam. ... Todos estes momentos se perderão no tempo... como lágrimas na chuva. Tempo de morrer".

A figura de Roy pode nos ajudar a pensar uma política que alinhave memória e educação. O que distingue Roy dos outros androides não é a capacidade de adquirir, armazenar e recuperar informações disponíveis fisicamente, mas a capacidade de significá-las por meio das experiências vividas. Nessa perspectiva, a memória em Roy se aproxima do sentido atribuído à memória não como recoleção objetiva dos fatos passados, mas como interpretação e construção, imaginação e composição. A memória ancora-se nas coordenadas espaço-tempo e nas mediações da linguagem. É o tempo narrado na história a partir das experiências e "a experiência é o que nos passa, o que nos acontece, o que nos toca. Não o que se passa, não o que acontece ou o que toca" (Larrosa, 2002, p. 21). Também a educação é uma prática enredada em interpretações e construções em que se baseiam outros sistemas de produção e manutenção de símbolos, significados e atitudes. No entendimento de Rocha e Tosta (2013), os processos socioeducativos constituem sistemas de elaboração e reprodução de símbolos, significados e atitudes vinculados a bens materiais e imateriais que se manifestam nas formas de pensar, agir, sentir, relacionar e lembrar. 


\section{pro.posições}

ISSN 1980-6248

Atualmente, a posição privilegiada que a memória e a educação conservam em uma história que tomou, simultaneamente, os professores como agentes mediadores da cultura e as instituições escolares como objetos da memória animou investimentos de diferentes tipos. Por um lado, o trabalho com depoimentos de professores, principalmente, por meio da prática da história oral e do uso da história de vida na formação docente produziu um repertório importante de pesquisas sobre a educação e a sua memória. Por outro, a criação de Centros de Memória e ou Documentação vinculados às faculdades e aos institutos de educação das principais universidades do País institucionalizou tanto essas iniciativas de produção de fontes quanto as iniciativas de levantamento, guarda e preservação de documentação histórica escolar e da educação. Ambos os empreendimentos beneficiaram o estudo de intelectuais ligados à educação e das instituições a partir das quais organizaram suas redes de sociabilidade.

A organização de Centros de Memória como o da Faculdade de Educação da USP (CME/FEUSP), em 1993, ou de programas desenvolvidos para a pesquisa histórica como o PROEDES-FE/UFRJ, foi uma realização exemplar nesse sentido. O papel de tornar acessível ao público um conjunto de dados, fontes e fundos documentais tem feito dessas iniciativas um apoio para a pesquisa e a formação. Foi nesse âmbito de preocupações que, em 2001, a Faculdade de Educação da Unicamp também criou o seu Centro de Memória da Educação. Conforme esclarece Martins (2004), ele tinha a finalidade de constituir "um espaço privilegiado para a formação dos professores e de educadores em geral, seguindo a premissa da formação do professor/pesquisador”(p. 7).

É a propósito do funcionamento desse espaço que queremos discutir aqui o seu sentido, bem como o modo de organizar o levantamento, a catalogação e a disponibilização de acervos sobre a educação, a escola e o ensino em articulação com os procedimentos de formação docente na universidade. Recentemente, ocupamos a coordenação do Centro de Memória da Educação da Faculdade de Educação da Unicamp, sustentando um projeto de "reavivamento" das bases sobre as quais ele foi conduzido desde 2001, de continuar as tarefas de organização do acervo de Júlio César de Mello e Souza (Malba Tahan), iniciadas em 2010, e de consolidação dos seus estatutos, aprovados em 2011. Isso tem significado atuar no sentido de dar arranjo e acesso a um arquivo pessoal, de criar dispositivos de referenciamento de outros acervos e instituições para subsidiar a pesquisa histórica na instituição e de discutir a presença de um Centro de Memória, articulado ao tipo de formação que a Faculdade de Educação administra. Em vez de um arrazoado das miudezas que esse trabalho implica, 


\section{pro.posições}

optamos por expor nossas inquietações diante delas. Dispomos em três seções o que pensamos defini-las.

Inicialmente, inquieta-nos ter a memória como tema de estudo. Depois, o lugar institucional proposto na FE/Unicamp para o estudo da memória educacional ainda é um desafio para a organização da pesquisa. Ficam postas as possibilidades pensadas para conduzir um programa de pesquisas, organizado em torno da dimensão educativa da memória. Finalmente, voltamo-nos para a função política que os estudos atribuem à memória para interrogar as atuais apostas do Centro de Memória da Educação da Faculdade de Educação da Unicamp.

Assim, com o objetivo de discutir algumas das possibilidades de estudo e de práticas em torno da memória docente e da educação, segue uma reflexão em torno do trabalho do Centro de Memória da Educação da FE/Unicamp no último quadriênio. Sobretudo, trata-se de uma tentativa de compreensão dos procedimentos metodológicos e dos conceitos que amparam tanto a organização do seu acervo quanto as pesquisas fomentadas a partir dos seus atuais propósitos de formação docente.

\section{A memória como tema de estudo}

Vê-se em Le Goff (2003) como o estudo da memória desempenha um papel crucial na interdisciplinaridade entre as ciências humanas e sociais. As contribuições de Freud, Goody, Gourhan, Halbwachs, Jacob, Nora, Piaget, Proust, e Ranger produziram entroncamentos importantes entre a psicologia, a antropologia, a sociologia, a história e a literatura para a conceituação da memória. Nesse sentido, comparece também a compreensão das lutas pela dominação da recordação, da tradição e da manifestação da lembrança que disseminou abordagens que vão da psicanálise à etno-história e da ciência à ficção, apontando a memória como instrumento e objeto de sentidos, mas também de poder. As obras de Bosi (1994, 2003), Ferro (1983), Meneses (1992), Pollak (1989) e Thompson (1998), por exemplo, discutem as criações, as apropriações e as dominações com que operam a recolha e as mutações da memória coletiva. 


\section{pro.posições}

Parte dessa discussão envolve uma topografia de lugares que Nora (1993) notou articular-se em instituições, monumentos, símbolos e funções e cuja análise frutificou entre nós. Na discussão sobre escolas e museus, ao refletirmos acerca dos arquivos ou da organização dos centros de memória, a referência às posições de Nora é reiterada. Sobretudo nessa perspectiva, a historiografia tem sublinhado a vontade de memória presente na sociedade que essas instituições manifestam e os usos da sua significação.

Também de outras perspectivas de análise, a questão dos usos da memória permanece importante. As leituras da obra de Benjamim, por exemplo, têm entendido a memória como busca atenciosa por opções de questionamento das relações e sensibilidades sociais do presente e do legado deixado pelo passado. Em Benjamin (1984), a educação e a memória são recobertas pelas asas da história alegoricamente figurada pelo olhar do anjo. Benjamim (1997) diz:

Há um quadro de Klee que se chama AngelusNovus que representa um anjo que parece querer afastar-se de algo que ele encara fixamente. Seus olhos estão escancarados, sua boca dilatada, suas asas abertas. O anjo da história deve ter esse aspecto. Seu rosto está dirigido para o passado. Onde nós vemos uma cadeia de acontecimentos, ele vê uma catástrofe única, que acumula incansavelmente ruína sobre ruína e as dispersa a nossos pés. Ele gostaria de deter-se para acordar os mortos e juntar os fragmentos. Mas uma tempestade sopra do paraíso e prende-se em suas asas com tanta força que ele não pode mais fechá-las. Essa tempestade o impele irresistivelmente para o futuro, ao qual ele vira as costas, enquanto o amontoado de ruínas cresce até o céu. Essa tempestade é o que chamamos progresso. (p. 141)

O anjo de asas abertas é arrastado para o futuro pela tempestade do progresso. Ele voa para o futuro, mas olha para trás e tenta buscar justificativas para os fragmentos, os resíduos e as ruínas que tal progressão deixou como legado. $O$ olhar do anjo é um olhar que julga o presente pelas avarias do passado. Como equacionar essa decalagem? Em Benjamin, uma das saídas é o trabalho da memória na história que, por meio da narrativa latente, inacabada e utilitária, alinhava passado, presente e futuro, considerando as experiências vividas e significativas.

A historiografia apresenta diversas outras delas. As reflexões de Foucault (2000), Le Goff $(1984,2003)$ e Nora (1993), por exemplo, sugerem o inverso, isto é, o trabalho da história sobre a memória como recurso de análise do passado. Trata-se, segundo Foucault (2000, p. 277), de fazer da história uma contramemória. Dubin (1999) e Namer (1987), entretanto, mostram que não só as narrativas, mas também os objetos materiais guardam e 


\section{pro.posıções}

solidificam a memória, garantindo-lhe presença, quando se vai mirar o passado. Ferro (1983) e Ricoeur (2007), por sua vez, lembram que a memória é tanto fonte quanto atributo da história e, por isso, insistem que proceder ao exame do presente a partir do recuo do passado exige interrogar os usos e os abusos desse exercício.

É significativo que entre nós, no Brasil, esses sejam problemas principalmente pensados no interior de instituições encarregadas do inventário das memórias por meio das quais, segundo Le Goff (2003), a história cresce. Já de algum tempo as análises acerca da memória e dos seus usos sociais, das técnicas mnemônicas ou das práticas da anamnese têm origem nessas instituições. Em museus, arquivos e centros de memória e documentação, o estudo do patrimônio material e imaterial tanto problematizou a solenidade das memórias impostas quanto buscou os refúgios das solidariedades mais espontâneas. Nesse processo, produziram-se análises bem-sucedidas sobre aquilo que a memória simboliza para o poder e para quem lhe resistiu. Em torno do Museu Paulista, do Museu de Arqueologia e Etnologia, do Instituto de Estudos Brasileiros e do Centro de Memória da Unicamp, para ficar apenas com alguns exemplos paulistas, gravitam edições, eventos e pesquisadores que contribuíram para o empreendimento. Porque as políticas para a ciência delegaram às universidades a maior responsabilidade sobre a produção e a divulgação da memória científica (Martins, 2004) e porque houve a necessidade de as pesquisas de diversos campos perguntar sobre o silêncio de muitos dos sujeitos da nossa história, a questão se consolidou como tema de estudos.

O acúmulo de reflexões em que atualmente se baseiam os empreendimentos de organização de acervos da educação, de educadores e das escolas indica-o. Os problemas sobre o passado colocados pela história cultural, as perguntas sobre as trajetórias de vida de professores ou os esforços para revitalizar histórias institucionais fizeram surgir não só Centros de Memória e Documentação, mas também pesquisas. Estudos como, entre tantos outros, os de Barletta (2005), Casalvara (2004), Neves (2005) e Zaia (2003, 2010), vão contribuindo para dar significado à capacidade de esse tipo de instituição adquirir, armazenar e recuperar acervos e interrogar experiências vividas. Os resultados desses esforços de compreensão do trabalho com o patrimônio e a história da educação consolidaram tanto espaços onde a cultura se faz memória como pesquisas que privilegiaram o estudo da memória como acervo e patrimônio. O Centro de Memória da Educação da Faculdade de Educação da Unicamp (CME/FE-Unicamp) participou desse esforço e, principalmente, produziu resultados do primeiro tipo. 


\section{pro.posições}

ISSN 1980-6248

Especialmente, Martins (2004, 2006) tratou deles. Em trabalhos sucessivos, insistiu na relação entre as questões dos arquivos escolares como locais de guarda e os propósitos e fins educacionais. Responsáveis pela organização dos acervos do Colégio Progresso Campineiro e da Escola Estadual Orozimbo Maia, Martins e Neves (2008) avaliaram que a constituição de acervos escolares não poderia estar distanciada das práticas sociais às quais pertencem ou pertenceram. Na prática, esse posicionamento não só tratou a escola como o espaço de arranjo do seu acervo, entendendo que a participação das pessoas dessas escolas na organização do acervo é elemento central no esforço de não fazer da memória uma panaceia reduzida ao arquivo ou a espaços "salva-guardadores de identidade" (Martins \& Neves, 2008, p. 44). Também fez do CME/FE-Unicamp uma instância de discussão da memória como tema e como referência para estudos culturais, artísticos e históricos (Martins, 2006, p. 49). Pensado a partir da compreensão de que atualmente a memória é um âmbito da luta pela cidadania, que constitui cidadania e as identidades culturais dos diferentes grupos sociais, o CME/FE-Unicamp, segundo Martins (2006), foi uma criação institucional atenta "às necessidades imperiosas de criar condições para o desenvolvimento de investigações e a formação em humanidades, de cumprir com o compromisso de salvaguardar fontes para que tais investigações sejam realizadas" (p. 54).

\section{O Centro de Memória da Educação como espaço do desejo}

$\mathrm{Na}$ área da educação, a valorização da memória como objeto de investigação não só animou a pesquisa histórica e a institucionalização de lugares para o estudo da memória. Também favoreceu o trabalho com a rememoração nos processos de formação docente e o interesse pelo testemunho como fiador da existência de identidades coletivas.

Do primeiro tipo, as iniciativas de Bueno, Catani e Sousa (2002), de Josso (2002) e de Souza e Mignot (2008), entre outros, mostram a fecundidade do uso dos relatos autobiográficos no processo de teorização acerca de intervenções desenvolvidas no preparo docente. As interfaces e as relações que examinam, entre a abordagem (auto) biográfica, as histórias de vida e as práticas de formação têm orientado a busca por modalidades mais significativas para o sujeito que exerce ou pretende exercer a docência. Trata-se de estudos que exploram a utilização das narrativas autobiográficas como opção metodológica para formação 


\section{pro.posições}

de professores e cuja contribuição para o entendimento das mudanças de representação sobre a docência é tanto teórica quanto prática.

Já as reflexões de Ferro (1983), Guimarães (2007) e Martins (2006), por exemplo, convidam ao outro tipo de trabalho. Elas remetem ao que Chartier (2009), a partir de Ricoeur (2007), identifica como elemento de certificação da história: “a crença na existência do passado tal como a assegura o testemunho da memória" (p. 23). E, sobretudo, resulta na preocupação em reconhecer o direito de coexistência de diferentes memórias. Tem resultado dessa preocupação um esforço reiterado para compreender o papel da memória nos vínculos que as identidades individuais mantêm com a identidade coletiva em uma sociedade na qual “essas identidades são fatores de diferenciação, mas também de submissão, de hierarquização e de deslegitimação social de grupos e indivíduos" (Martins, 2006, p. 53.). Nesse sentido, perceber, nos discursos testemunhais, os conhecimentos subjugados, tanto nos espaços formais de educação como nos não formais é fundamental para criar possibilidades de transformação das atuais práticas de formação. Pois, segundo avalia Guimarães (2007):

Revisitar o passado não pode ser desvinculado das demandas e exigências de um tempo presente e, nesse sentido, sua compreensão é também parte da inteligibilidade de uma cultura histórica que aciona experiências, imagens e atores do passado para uma contemporaneidade que busca nesse tempo que ficou para trás referências para imaginar o mundo em que vive. (p. 39)

Em ambos os tipos de trabalho, "o regime de crença que governa a fidelidade da memória" cumpre um papel equivalente na análise ao da "epistemologia da verdade que rege a operação historiográfica". No entanto, como esclarece Chartier (2009), em vez de se inscrever na ordem de um saber universalmente aceitável, científico, no sentido de Certeau, os trabalhos são conduzidos "pelas exigências existenciais das comunidades para as quais a presença do passado no presente é um elemento essencial da construção do seu ser coletivo” (p.24).

O trabalho que atualmente é desenvolvido com o acervo Malba Tahan tem natureza diversa. Por um lado, envolve conservação material, arranjo e classificação. Por outro, organiza-se em função da pesquisa histórica e dos seus critérios de certificação. Ocorre que, na forma como o CME/FE-Unicamp foi concebido, o trabalho com a rememoração e o interesse pelos testemunhos merecem seu espaço de pesquisa. O conjunto de depoimentos e lembranças que o projeto Memória Viva (2012-2013) produziu durante as celebrações dos 40 anos da Faculdade de Educação, de alguma maneira, mostra-o. O período de mudanças 


\section{pro.posições}

provocado pelo processo de reforma do programa de pós-graduação em Educação da Unicamp em 2013 e a progressiva recomposição do quadro docente trouxeram também um maior interesse, senão acerca da identidade institucional, ao menos dos tipos de tradição que identificam a docência e a pesquisa nesta Faculdade. Como as pesquisas com os acervos escolares já mostraram, suspeitamos que também nas instituições de formação de professores em nível superior há uma história dos métodos e dos procedimentos de ensino muito pouco conhecida.

De fato, o modo como a universidade forma professores tem uma história que, em geral, se organizou em torno dos cursos de licenciatura e pedagogia das suas atuais Faculdades de Educação. Em Campinas, temos reconhecido que voltar o olhar com o qual organizamos e pesquisamos os acervos escolares para o lugar onde nós mesmos formamos docentes significa lidar com desafios do mesmo tipo. Sobretudo, temo-nos interrogado acerca das práticas de formação que se consolidaram nas quatro décadas de funcionamento da Faculdade de Educação da Unicamp. E, como é comum também nas escolas, não encontramos organizado mais que a documentação proveniente das atividades-meio da instituição: documentos administrativos e funcionais. Conforme argumenta Vidal (2005, 2007), os historiadores da educação têm enfatizado o cuidado em conservar documentos escolares gerados em outros âmbitos que não o administrativo, colocando o problema da preservação de fontes de pesquisa relativas às atividades-fim da escola. Iniciativas nessa direção responderiam aos atuais interesses da pesquisa histórica acerca das relações de ensino-aprendizagem na escola. $\mathrm{Na}$ universidade, encontramos lacunas do mesmo tipo, faltam fontes fundamentais para a percepção das relações pedagógicas realizadas cotidianamente.

Sob esse aspecto, criar condições de preservação de documentos rotineiramente produzidos nas atividades pedagógicas é, para a universidade, um recurso para viabilizar a construção de análises sobre a formação de professores no último meio século. Na Faculdade de Educação da Unicamp, essa discussão aparece junto com a revisão do regimento do Centro de Memória da Educação, ganhando força com a realização do projeto Memória Viva. Mais uma vez, para efetivar isso, as tarefas que então se impõem são semelhantes aos problemas da preservação de fontes de pesquisa relativas às atividades-fim da escola e que vão desde conseguir recursos materiais e humanos para as tarefas de conservação documental e acondicionamento até construir planos de destinação. 


\section{pro.posições}

Tanto quanto a compreensão dos modos como formamos para a docência nas últimas quatro décadas, a coleta de testemunhos sobre diferentes processos de escolarização e o trabalho com a rememoração na formação de professores desafiam a atual organização do CME/FE-Unicamp. São domínios para os quais já há acúmulo de pesquisas quanto aos procedimentos e as metodologias, mas que dependem da articulação de equipes cada vez mais numerosas de especialistas - dificuldade inicial de organização do Centro de Memória da Educação que ainda nos embaraça na tarefa de converter o Centro num espaço para diferentes propostas de trabalho e investigação.

\section{Os usos da memória e as instâncias da sua institucionalização}

A organização das atividades do Centro de Memória da Educação da FE/Unicamp vem se beneficiando da discussão sobre o papel da memória na relação representativa do presente com o passado. Reparte-se em preocupações com o estudo das principais instâncias de institucionalização da memória educacional: a pesquisa histórica da docência e o trabalho com a rememoração nos processos de formação de professores; a atenção à memória que se conserva em museus pedagógicos, centros de documentação do ensino, arquivos escolares e bibliotecas; e a busca pelos vestígios da memória no campo da ação política consolidaram um plano de atividades pensado a partir de quatro frentes.

A primeira delas diz respeito às práticas de entesouramento da memória de si, aos arquivos pessoais e aos relatos autobiográficos de professores. Há como que um entroncamento de fazeres sobre o tempo que tem nos gestos de registrar, guardar e relembrar os meios de assegurar a memória por meio de uma inteligibilidade controlada. Arquivar a própria vida, como propõe Artières (1998, p. 32), ou falar da própria experiência e do seu passado, conforme percebe Henry Rousso (2006, p. 99), é parte de uma construção para si mesmo de uma identidade a partir de representações em disputa sobre o social e em torno delas. Nesse sentido, encarregar-se da compreensão das condições em que se constrói para si uma "memória instrumental" está no âmago das atividades e das pesquisas em torno de 


\section{pro.posições}

arquivos pessoais e de testemunhos acerca da experiência docente em desenvolvimento no Centro de Memória da Educação da Unicamp ou nele apoiadas. ${ }^{1}$

Depois, uma segunda frente se abriu para pensar o patrimônio acadêmico-científico da Unicamp. Ela resulta da suspeita de que falávamos mais acima a respeito da fragilidade da conservação dos registros acerca das atividades-fim das nossas faculdades e dos institutos. $\mathrm{O}$ forte investimento do Centro de Memória da Educação em períodos anteriores, na pesquisa com acervos escolares de instituições centenárias de Campinas, permite ver o quanto os estudos sobre o ensino e a formação de professores na Unicamp se ressentem da mesma atenção. Assim, o acumulado de pesquisas que já temos reunido a respeito da cultura escolar (Faria Filho, Gonçalves, Vidal, \& Paulilo, 2004), da organização de arquivos escolares (Zaia, 2010) e da força educativa do trabalho com a memória (Martins, 2006) vai sendo mobilizado ultimamente para também subsidiar a compreensão das condições de que dispomos para historiar as maneiras de a universidade formar. ${ }^{2}$

Outra frente de atuação do Centro de Memória da Educação da Unicamp tem sido a investigação do que Ulpiano Meneses (1992) uma vez identificou como "vertiginosa expansão da memória no campo da cultura material" (p.13). Suas preocupações com o objeto antigo, sobretudo, advertem que a memória porventura evocada a partir dele não dá conta do passado, mas, antes, dos processos de sua tesaurização no presente. Gerard Namer (1987) sugere uma compreensão das bibliotecas no mesmo sentido que Meneses, ao reivindicar para o livro o estatuto de um artefato passível de entesouramento. Dessa forma, voltar-se para laboratórios, bibliotecas e museus pode ser entendido como um meio de estudo não só da história da cultura material ou das práticas de ensino e pesquisa, mas da própria memória e dos seus atuais processos de tesaurização. ${ }^{3}$

\footnotetext{
1 Atualmente, no Centro de Memória da Educação da Unicamp, a pesquisa de Claudiana dos Reis de Sousa Morais com o acervo pessoal de Júlio César de Mello e Souza trata das formas como esse professor conservou os registros do seu trabalho intelectual e docente. Por outro lado, no projeto de comemoração dos 40 anos da Faculdade de Educação Memória Viva, conduzido pela professora Ana Smolka, o Centro de Memória apoiou o trabalho de registro de depoimentos de ex-alunos, professores e diretores aposentados no sentido de subsidiar a elaboração de uma política de preservação da memória institucional.

2 O trabalho de conclusão de curso de Aline Rodrigues da Silva, intitulado A luta do Conselho de Entidades de Campinas por uma Faculdade de Medicina na cidade, apresenta, a partir de documentação do SIARQ, resultados úteis sobre a criação da Faculdade de Ciências Médicas da Unicamp e sua importância para a organização de uma universidade pública em Campinas.

${ }^{3}$ No Centro de Memória, os recentes estudos de Alexandro Henrique Paixão (2011), no Real Gabinete Português de Leitura, redimensionam algo dessa discussão, ao se deter sobre o papel de lugar de práticas e atuação de uma biblioteca. Trabalhos como os de Franciele Fernanda Amaral sobre a Biblioteca Prof. Joel Martins, da Faculdade
} 


\section{pro.posições}

ISSN 1980-6248

Há, ainda, uma última face das atividades de pesquisa organizadas a partir do CME/FE-Unicamp a considerar, aqui, que diz respeito ao modo como Ricoeur (2007) percebe a memória como compromisso ético-político. Entre as diferentes tipificações da memória de que trata Ricoeur (2007, pp. 458-459), a discussão da relação entre o esquecimento e a memória manipulada é aquela que melhor põe em causa os questionamentos e as dúvidas das novas gerações diante da história. Ricoeur trata de experiências extremas - a guerra, o holocausto, a tortura -, mas, com elas, faz ver o quanto pode a história contra o manejo da falsificação do passado, a manipulação ideológica da memória e as artimanhas das omissões, cegueiras e negligências. Nesse sentido, a história é parte "do caminho da reconquista pelos agentes sociais do domínio de sua capacidade de fazer narrativa de modo ao mesmo tempo inteligível, aceitável e responsável" (Ricoeur, 2007, p 456). Essa eficácia operatória que Ricoeur atribui à historiografia lhe parece capaz de opor-se à passividade desculpatória diante da parte intransmissível de uma experiência extrema a inquietação.

Essa dimensão de compromisso ético-político da vontade de lembrar que a memória adquire nas reflexões de Ricoeur tem sido pensada atualmente no Centro de Memória da Educação da Unicamp com o propósito de lidar com as palavras vindas a propósito do exercício da docência e as escritas em que já se recolhem os vestígios documentários dessa experiência e de repensar o acumulado de reflexões em que se basearam os atuais empreendimentos de organização de acervos da educação, dos educadores e das escolas a partir de uma perspectiva atenta a essa "eficácia operatória" da história no campo da memória de que fala Ricoeur. De ambos os modos, no entanto, importa dimensionar os efeitos e o alcance daquilo que escolhemos memorializar em arquivo, currículo ou narrativa. ${ }^{4}$

Do mesmo modo que a noção de compromisso ético-político da vontade de lembrar proposto por Ricouer, as ideias de "entesouramento de si" e de "processo de tesaurização" têm servido de fundamento ao trabalho realizado no CME/FE-Unicamp. Por um lado, a

de Educação/Unicamp e de Paula Ferreira de Souza acerca do Projeto Memória da Educação do Arquivo Público do Estado de São Paulo oferecem bons exemplos do esforço do Centro de Memória da Educação de fomentar essas questões como tema de pesquisa.

${ }^{4}$ Com essa preocupação, o projeto Acervos históricos de educação e da escola em Centros de Memória e de Documentação civis e militares, que, atualmente, conta com financiamento $\mathrm{CNPq}$, tem insistido nas ideias de Le Goff, Nora, Bosi, Cook e Meneses acerca do papel ativo dos agentes da memória, como o são os arquivistas, os bibliotecários, os historiadores, os museólogos e, também, os velhos, os docentes, os adolescentes, as lideranças políticas, etc., para o estudo de diferentes processos de construção da memória histórica acerca de educadores, escolas ou práticas escolares. No âmbito deste projeto, a pesquisa em acervos de tipos e proveniências diferentes constituiu uma amostragem sobre a qual se pode tratar dos limites da comparação e experimentar estratégias variadas de seriação das fontes. 


\section{pro.posições}

compreensão de que a memória também designa um fracionamento da memória social, o reconhecimento de identidades parciais e antiunificavéis (Ribeiro, 2000, p. 37) faz do entesouramento da própria memória uma prática de produção de arquivos pessoais. Como categoria de análise, a noção de entesouramento de si permite problematizar os artifícios e os subterfúgios utilizados na guarda de documentos de caráter pessoal para, depois, pleitear custódia em instituições públicas. Por outro, a noção de "processo de tesaurização" chama a atenção para as práticas de classificação das fontes documentais e artefatos do passado de acordo com uma visão de mundo, de um sistema de valores congênito ao da instituição de guarda. Dessa perspectiva, também é uma noção que permite analisar o sentido de representação concreta que uma cultura mantém com o passado e de elo entre a memória e as novas leituras do contemporâneo.

Não parece um despropósito pensar, então, que é justamente contra a impossibilidade do entesouramento de si e de reconhecer-se nos processos de tesaurização do futuro, ao qual pertence, que Roy Batty se revolta na ficção filmada por Ridley Scott.

A luta vã de Roy Batty contra a finitude em Blade Runner é também um desejo de memória, revolta contra os momentos que se perderão no tempo. Lembra-nos de que a memória é uma instância da luta política, que resiste e, assim, conserva identidades, por vezes, apenas graças às tradições orais, mímicas ou alimentares (Ferro, 1983). Os empreendimentos de Ricoeur (2007) e também de De Decca (1981), Ferro (1983) e Vesentini (1997) nesse sentido já mostraram o que o esquecimento significa na luta contra o poder.

\section{Considerações finais}

No caso da institucionalização da memória em arquivos ou centros de pesquisa e documentação, Cook (1998) é perspicaz ao refletir acerca das implicações políticas da memória quando vaticina: "O controle do passado, e o controle sobre a criação e preservação do passado pelos arquivos, reflete as lutas de poder do presente e, na verdade, sempre as refletiram" (p. 143). De uma perspectiva desse tipo, a pesquisa e o entendimento das funções e das atividades dos criadores de arquivos, os processos de geração de registros para que os arquivos possam ser criados são de vital importância na construção da memória coletiva. 


\section{pro.posições}

Portanto, diante do que se julgou merecer ser lembrado e da maneira de fazê-lo, é exigido reconhecer a própria historicidade do CME/FE-Unicamp e o seu papel ativo na construção da memória. Nunes e Carvalho (1993) notam que as instituições portadoras de acervos têm trajetórias próprias que impregnam a documentação recolhida. Conforme explicam, os arquivos reportam “às formas concretas, singulares, e 'contaminadas' de articulação de saberes implícitos e que se corporificam em práticas classificatórias diferenciadas das fontes” (pp. 28-29). É significativo reconhecer que as prioridades e os mecanismos institucionais de acolhimento, preservação, restauração, classificação e identificação da documentação e o estabelecimento das suas condições de acesso têm a ver com a própria história do lugar de guarda e das práticas em que se apoia. Como faz Cook (1998, p. 142), também no Centro de Memória da Educação, atualmente, assumiu-se que, ao constituir fundos de documentação, não se preserva passivamente as fontes que foram entregues. Criam-se para elas formas, filtros e arranjos de compreensão da sua organicidade.

Nessa ideia da construção da memória educativa, parece-nos complementar às tarefas de organização dos acervos e de criação de processos de registro e produção das fontes subsidiar o docente a perceber o seu passado e do seu ofício como elemento formador. Por um lado, pensamos na razão que tem a proposição de Calligaris (1998) sobre o fato de haver na modernidade ocidental "uma cultura na qual se espera que do sujeito venha a organização do mundo (e não do mundo a organização do sujeito)" (p. 46). E, portanto, a relevância de se conceber a própria vida não como uma confirmação das regras e dos legados da tradição, mas como uma aventura para ser inventada (Calligaris, 1998, p. 46). Os trabalhos com relatos autobiográficos de professores já mostraram a importância desse caráter de excepcionalidade no registro das suas histórias de vida. Por outro, temos em vista a capacidade das representações do passado propostas pela memória coletiva produzir, moldar e organizar a experiência. Nesse caso, importou fazer do Centro um espaço de formação capaz de vincular as necessidades de afirmação ou de justificação de uma identidade profissional para aquele que exerce a docência às contribuições do saber histórico (Mazza \& Zamboni, 2015). Assim como Ridley Scott sugere em Blade Runer, pensamos que é associada à capacidade de lembrar que a vivência adquire sentido. E, ainda que a nossa sorte não seja diferente da de Roy, poder situarse no passado é abrir um espaço próprio para o presente (Certeau, 2007), dar outra vida para a interpretação (Vesentini, 1997), contentar-se com a condição humana (Ricoeur, 2007). 


\section{pro.posıções}

ISSN 1980-6248

\section{Referências Bibliográficas}

Alves, G. (2004). Blade Runner. O caçador de Andróides. De Ridley Scott, 1982. In Projeto de Extensão Tela Crítica. Retirado em 20 de abril de 2014, de http://www.telacritica.org/BladeRunner.htm.

Artiéres, P. (1998). Arquivar a própria vida. Estudos Históricos, 11(21) 9-34.

Barletta, J. M.(2005). O lugar dos objetos no arquivo: materiais escolares. Dissertação de Mestrado em Educação, Faculdade de Educação, Universidade de São Paulo, São Paulo.

Benjamin, W. (1984). Reflexões sobre a criança, o brinquedo e a educação. São Paulo: Summus.

Benjamin, W. (1997). Magia e técnica, arte e política (4a ed.). São Paulo: Brasiliense.

Bosi, E. (1994). Memória e sociedade: lembranças de velhos. São Paulo: Companhia das Letras.

Bosi, E. (2003). O tempo vivo da memória: ensaios de psicologia social. São Paulo: Ateliê Editorial.

Bueno, B., Catani, D. B., \& Sousa, C. P. (Orgs.). (2002). A vida e o ofício dos professores: formação contínu, autobiografia e pesquisa em colaboração. São Paulo: Escrituras.

Calligaris, C. (1998). Verdades de autobiografias e diários íntimos. Estudos Históricos, 11(21), 3543.

Casalvara, T. da S. (2004). Práticas da educação libertária no Brasil: a experienciada Escola Moderna em São Paulo. Dissertação de Mestrado em Educação, Faculdade de Educação, Universidade de São Paulo, São Paulo.

Certeau, M. de. (2007). A escrita da bistória (2a ed.). Rio de Janeiro: Forense.

Chartier, R. (2009). A bistória on a leitura do tempo. Belo Horizonte: Autêntica.

Cook, T. (1998). Arquivos pessoais e arquivos institucionais: para um entendimento arquivístico comum da formação da memória em um mundo pós-moderno. Estudos Históricos, 11(21), 129-150.

De Decca, E. (1981). O silêncio dos vencidos: memória, história e revolução. São Paulo: Brasiliense.

Deeley, M. (Produtor), \& Scott, R. (Diretor). (1982). Blade Runner: o caçador de Andróides. Estados Unidos. 


\section{pro.posıções}

ISSN 1980-6248

Dubin, S. (1999). Display of Power: memory and amnésia in the american museum. New York: New York University Press.

Faria Filho, L. M. de, Gonçalves, I. A.,Vidal, D. G, \& Paulilo, A. L (2004, janeiro/abril). A cultura escolar como categoria de análise e como campo de investigação na história da educação brasileira. Educação e Pesquisa, 30(1), 139-159.

Ferro, M.(1983). A manipulação da bistória no ensino e nos meios de comunicação: a bistória dos dominados em todo o mundo. São Paulo: Ibrasa.

Foucault, M.(2000). Nietzsche, a genealogia, a história. In M. Foucault, Arqueologia das ciências e bistória dos sistemas de pensamento (pp. 260-281). Rio de Janeiro: Forense.

Guimarães, M. L. S. (2007). O presente do passado: as artes de Clio em tempos de memória. In M. Abreu, R. Soihet, \& R. Gontijo (Orgs.), Cultura política e leituras do passado: historiografia e ensino de história (pp. 23-42). Rio de Janeiro: Civilização Brasileira.

Josso, M.-C. (2002). Experiência de vida e formação. Lisboa: Educa.

Larrosa, J. (2002). Notas sobre a experiência e o saber da experiência. Revista Brasileira de Educaşão, 19, 20-28.

Le Goff, J. (1984). Documento/Monumento. In Enciclopédia Einaudi. Lisboa: Imprensa Nacional Casa da Moeda.

Le Goff, J. (2003). História e memória. Campinas: Ed. da Unicamp.

Martins, M. do C. (2004). Os desafios para a organização do Centro de Memória da Educação da Unicamp, ou de como constituir coletivamente um lugar de memória. In Anais do $V$ Congresso Luso-Brasileiro de História da Educação, Universidade de Évora, Évora. Retirado em 23 de julho de 2013, de http://www.fe.unicamp.br/servicos/centro_ memoria/pesquisa/evora.pdf.

Martins, M. do C. (2006, setembro). Em busca del tiempo perdido: La memória de La educación. Educación y ciudad, 10, 43-62.

Martins, M. do C., \& Neves, R. X. (2008). Fontes de pesquisas escolares e formação da memória educacional. In M. do C. Martins, E. Zamboni, H. P. Rocha, M. C. B. Galzerani, \& V. L. S de Rocha (Orgs.), Memórias e histórias da escola (pp. 35-50). Campinas: Mercado de Letras. 


\section{pro.posıções}

Martins, M. do C., \& Rocha, H. H. P. (2005, julho/dezembro) Lugares de memória: sedução, armadilhas, esquecimento e incômodos. Horizontes, 23(2) 91-99.

Meneses, U. T. B. de. (1992). A história, cativa da memória? Para um mapeamento da memória no campo das ciências sociais. Revista do Instituto de Estudos Brasileiros, 34, 9-24.

Namer, G. (1987). Mémoire et sociéte. Paris: Meridiens/Klinckinik.

Neves, R. X. (2005). As possibilidades educacionais nos centros de documentação e memória. Dissertação de Mestrado em Educação, Unicamp, Campinas.

Nora, P. (1993, dezembro). Entre memória e história: a problemática dos lugares. Projeto História, 10, 7-28.

Nunes, C., \& Carvalho, M. M. C. de. (1993, setembro). Historiografia da educação e fontes. Cadernos Anped, 5, 7-64.

Paixão, A. H. (2011). Notes sur la réception d'Alexandre au Brésil au XIX e siècle. Cabiers Alexandre Dumas, 38, 126-133.

Pollak, M.(1989). Memória, esquecimento, silêncio. Estudos Históricos, 2(3), 3-15.

Ribeiro, A. P. G. (1998). Mídia e História: ambigüidades e paradoxos. In XXI Congresso Brasileiro de Ciências da Comunicação. Recife.

Ricoeur, P. (2007) A memória, a bistória, o esquecimento. Campinas: Ed. da Unicamp.

Rocha, G., \& Tosta, S. P.(2013). Antropologia \& Educação. Belo Horizonte: Autêntica.

Rousso, H. (2006). A memória não é mais o que era. In M. de M. Ferreira, \& J. Amado (Orgs.), Usos e abusos da História Oral (8a ed., pp.93-102). Rio de Janeiro: FGV Editora.

Souza, E. C. de, \& Mignot, A.C.V. (Orgs.). (2008). História de vida e formação de professores. Rio de Janeiro: Quartet.

Suppia, A. L.(1997). Limite de alerta! Fição cientifica (FC) em atmosfera rarefeita. Uma introdução ao estudo da FC no cinema brasileiro e em algumas cinematografias off Hollywood. Tese de Doutorado, Instituto de Artes, Universidade, Estadual de Campinas, Campinas.

Thompson, P.(1998). Voz do passado: história oral. Rio de Janeiro: Paz e Terra.

Vesentini, C. A.(1997). A teia do fato. São Paulo: Hucitec. 


\section{pro.posições}

Vidal, D. (2005). Cultura e práticas escolares: uma reflexão sobre documentos e arquivos escolares. In R. F. Souza, \& V. T. Valdemarin (Orgs.), A cultura escolar em debate: questões conceituais, metodológicas e desafios para a pesquisa (pp. 3-30).. Campinas: Autores Associados.

Vidal, D. (2007). Por uma ampliação da noção de documento escolar. In M. I.M. Nascimento, W. Sandano, J. C. Lombardi, \& D. Saviani (Orgs.), Instituições escolares no Brasil: conceito e reconstrução bistórica (pp. 59-74). Campinas: Autores Associados.

Zaia, I. B. (2003). A história da educação em risco: avaliação e descarte dos documentos do arquivo da escola de aplicação. Dissertação de Mestrado em Educação, Faculdade de Educação, Universidade de São Paulo, São Paulo.

Zaia, I. B. (2010). Escrituração escolar: produção, organização e movimentação de papéis nas escolas públicas paulistas. Tese de Doutorado em Educação, Faculdade de Educação, Universidade de São Paulo, São Paulo.

Submetido à avaliação em 10 de setembro de 2014; aceito para publicação em 16 de janeiro de 2016. 
